\title{
The Landscape Ecology of Rivers: from Patch-Based to Spatial Network Analyses
}

\author{
Tibor Erös ${ }^{1}$ (D) Winsor H. Lowe ${ }^{2}$
}

Published online: 16 November 2019

(C) The Author(s) 2019

\begin{abstract}
Purpose of Review We synthesize recent methodological and conceptual advances in the field of riverscape ecology, emphasizing areas of synergy with current research in landscape ecology.

Recent Findings Recent advances in riverscape ecology highlight the need for spatially explicit examinations of how network structure influences ecological pattern and process, instead of the simple linear (upstream-downstream) view. Developments in GIS, remote sensing, and computer technologies already offer powerful tools for the application of patch- and gradient-based models for characterizing abiotic and biotic heterogeneity across a range of spatial and temporal scales. Along with graph-based analyses and spatial statistical stream network models (i.e., geostatistical modelling), these approaches offer improved capabilities for quantifying spatial and temporal heterogeneity and connectivity relationships, thereby allowing for rigorous and highresolution analyses of pattern, process, and scale relationships.

Summary Spatially explicit network approaches are able to quantify and predict biogeochemical, hydromorphological, and ecological patterns and processes more precisely than models based on longitudinal or lateral riverine gradients alone. Currently, local habitat characteristics appear to be more important than spatial effects in determining population and community dynamics, but this conclusion may change with direct quantification of the movement of materials, energy, and organisms along channels and across ecosystem boundaries - a key to improving riverscape ecology. Coupling spatially explicit riverscape models with optimization approaches will improve land protection and water management efforts, and help to resolve the land sharing vs. land sparing debate.
\end{abstract}

Keywords Patch-based models · Gradient models · Spatial statistical network models · Network analyses · Stream networks · Riverscapes

\section{Introduction}

Landscape ecology aims to elucidate the effects of large-scale variation in the structure and composition of habitat on ecological patterns and processes across a range of spatiotemporal scales $[1,2]$. The discipline of landscape ecology originated in terrestrial systems and, traditionally, aquatic ecosystems were

This article is part of the Topical Collection on Landscape Ecology of Aquatic Systems

Tibor Erős

eros.tibor@okologia.mta.hu

1 MTA Centre for Ecological Research, Balaton Limnological Institute, Klebelsberg Kuno u. 3, Tihany H-8237, Hungary

2 Division of Biological Sciences, University of Montana, Missoula, MT 59812, USA considered components of the larger landscape mosaic, or as subunits linked to the terrestrial landscape by cross-ecosystem flows of material and energy [3]. However, it was soon recognized that landscape ecology questions are relevant within aquatic systems as well [3-5]. Differences in the environmental characteristics of terrestrial vs. aquatic systems may necessitate the use of different metrics and methods for quantifying the landscape mosaic. However, the overarching goal of quantifying effects of large-scale environmental heterogeneity on ecological patterns and processes - the cornerstone of landscape ecology as a discipline-is applicable across realms. Furthermore, there can be no doubt that efforts to unify landscape ecology research across terrestrial-aquatic boundaries will advance both the conceptual and methodological tools of the discipline $[3,6]$.

The purpose of this review is to summarize significant recent developments related to the landscape ecology of running 
waters (i.e., "riverscapes," which includes the interconnected habitats of streams, rivers, and riparian zones, sensu Fausch et al. [7]). Specifically, we use core research topics of recent landscape ecology (Fig. 1; [2]) as a framework for reviewing new and interesting findings related to the following three questions: (Q1) How do the quality, configuration, and connectivity relationships of patches (i.e., units of heterogeneity) change across spatial and temporal scales in riverscapes? (Q2) How do changes in these features influence ecological patterns, processes, and scale relationships in riverscapes? (Q3) How can knowledge about scale-dependent patterns and processes improve management decisions about the sustainable use of specific patches and entire riverscapes (i.e., conservation and provision of ecosystem services)?

\section{Q1: The Heterogeneity of Riverscapes}

\section{Riverscapes as Networks}

From a human perspective, riverscapes are linear dendritic or anabranching systems; the spatial configuration and structure of which differ markedly from most terrestrial systems and other aquatic systems (i.e., lakes, ponds, and marine environments). The hierarchical branching structure of river networks has long been recognized, but most research in these systems occurred within linear branches of the network (i.e., individual stream channels), ignoring spatial relationships among branches within the larger network, connectivity among and within branches, and flow-mediated directionality of the network (non-network analysis, sensu Peterson et al. [8••]). Even the River Continuum Concept (hereafter RCC, Vannote et al. [9]), perhaps the most influential concept in stream ecology in the twentieth century, did not consider river systems as networks but instead predicted patterns and processes along linear channels spanning the longitudinal profile of systems, from headwaters to mouth. Recent conceptual advances, in contrast, emphasize the need for spatially explicit examinations of ecological processes in river networks, with particular emphasis on how network structure influences ecological patterns and processes $[10-13,14 \bullet]$. Along with this recognition come novel approaches for quantifying the ecological effects of network structure and habitat quality, configuration, and connectivity, which we outline below.

\section{Patch vs. Gradient Models of Riverscapes}

Two fundamental approaches exist for quantifying and modelling landscape structure and its effects on species and
Q1

Heterogeneity

Spatial analysis
Q2

Pattern, process, scale
Q3 Management issues

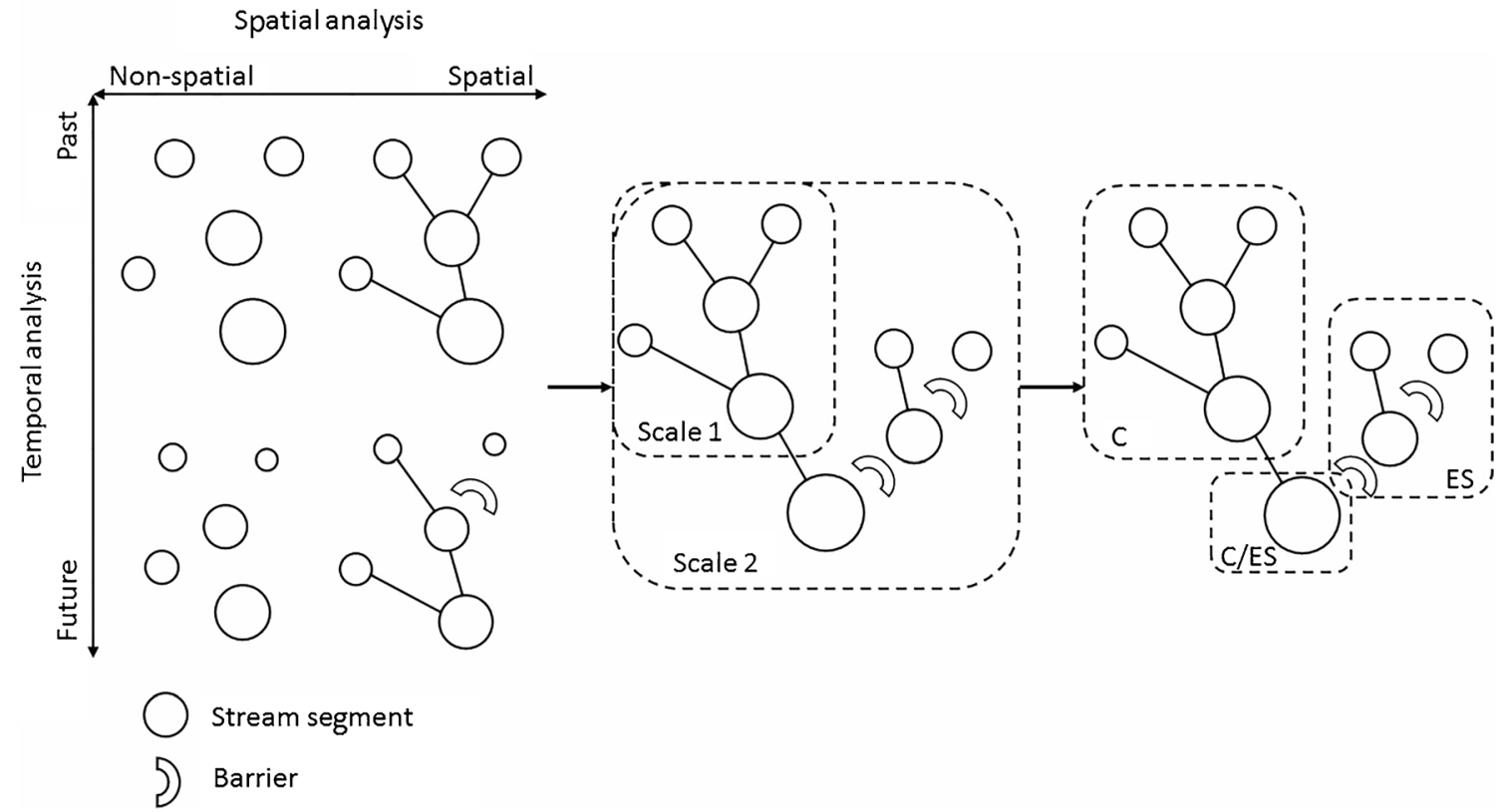

Fig. 1 A framework of core landscape ecological research topics (after Wu 2013), using a simple graph-based model. Q1 addresses the quantification of ecological heterogeneity of riverscapes. Spatial analyses include the characterization of the habitat (e.g., size, quality, configuration, connectivity). Analyses can be ordered along a gradient from spatially independent examinations of patch quality to more developed spatial analyses (e.g., graph-based models). Temporal analyses characterize past, present, and future conditions of the habitat (e.g., from analyses of patch history to predictions of climate changes effects). Q2 relies on analyses of spatial and temporal heterogeneity to understand process-pattern relationships and effects of scale. These analyses are a prerequisite to address Q3, management issues (e.g., optimizing the spatial allocation of protected areas or resources for conservation $[\mathrm{C}]$ or other ecosystem services $[\mathrm{ES}]$ ) 
communities: patch-based and gradient models [15]. Patchbased models, as the name implies, treat the landscape as a set of habitat patches representing environmentally homogenous subunits of the landscape. Landscape structure thus emerges from the composition, configuration, and connectivity relationships of patches with different sizes and qualities $[15,16]$. In contrast, gradient models represent landscape structure based on continuous raster or grid data, without a priori delineation of patches or subunits. Here, grid cells or pixels are the smallest homogenous and discrete spatial units, allowing for a quasi-continuous change of characteristics across the landscape $[15,17]$.

Both patch-based and gradient models have been successfully applied to river networks. For example, as an alternative to the RCC view that biotic communities are controlled predominantly by continuous, longitudinal gradients in physical conditions, patch-based models have shown that discontinuous hierarchies of hydrogeomorphic patches can strongly influence on the spatial structure and composition of communities [18-20]. The spatial arrangement and temporal dynamics of these hydrogeomorphic patches (or "functional process zones," sensu [21]) provide a useful template for the delineation of local communities in the river network, and a spatially explicit framework for environmental management [13, 21-23].

Recent developments in GIS, remote sensing technologies, and computer power offer powerful tools for the application of gradient models, too [24, 25]. For example, Scown et al. [26] applied airborne laser scanning (LiDAR) technology to measure spatial patterns in riverscape topography using moving window analyses of eight surface metrics at a resolution of $1 \mathrm{~m}^{2}$. The increasing availability of unmanned aerial vehicles (UAVs) has enabled the production of high-quality topographic data with a spatial resolution up to $10 \mathrm{~cm}$ and a vertical error to $50 \mathrm{~cm}[25,45]$. Even very basic UAVs can yield data on the complexity of riverscapes - including geomorphological, hydraulic, and ecological attributes - far beyond traditional field methods in resolution, accuracy, and efficiency [27]. With these rapidly developing technologies, not only single reaches (i.e., $\approx 100 \mathrm{~m}$ of channel length), but also the entire segments, subcatchments, and even whole catchments can be routinely surveyed in a standardized manner [28]. Data obtained from these spatial surveys will enable a better understanding of biogeomorphological patterns and processes at a wide range of scales, and may lead to more effective quantification of the links between hydromorphological conditions and ecological status of the riverscape [28, 29].

Similar to terrestrial systems, the decision to use patchbased or gradient models depends on study goals and the underlying structure of environmental heterogeneity $[6,15$, $30,31]$. Generally, patch-based models are useful when both intra-patch environmental homogeneity and inter-patch environmental heterogeneity are high and observable. When these criteria are not met, gradient models are preferred. Due to the small size of sampling units (i.e., grids or cells), gradient models can be applied across spatial scales using a range of continuous variables and moving window analyses to examine the effect of scale on ecological pattern and process [17]. However, results from gradient models may be difficult to apply to management when the continuous response variables do not have intuitive interpretations, or when the spatial resolution of model output does not match the scale of management ( $[15,31]$ but see, e.g., Baranya et al. [32]). Nevertheless, the accuracy and availability of technology for continuous environmental measurements are increasing rapidly, suggesting that gradient models will remain at the forefront of riverscape analyses $[25,32]$.

Graph analyses may be a useful modelling approach for riverscape ecology that overcomes the limitations of patchbased and gradient models while enhancing the interpretability and applicability of results $[33,34]$. Briefly, graphs are a set of nodes and links. In landscape ecological applications, nodes can represent a particular environmental feature of habitat patches, a focal species, or an assemblage of species, whereas links represent the functional connections among nodes, such as the strength of interactions among species, the flow of energy among patches, or the dispersal of individuals among populations or communities [35-37]. Graphs can be depicted using patch-based, grid, or raster data. Using this modelling template, researchers can then apply graph-based indices to characterize ecological patterns and processes in a spatially explicit manner with simple, straightforward extensions to management. Despite relatively long-standing applications in terrestrial landscape ecology, graph analyses have only recently been applied in riverscape ecology (see, e.g., $[13,38-40)$. We return to this modelling tool below, in discussing methods for quantifying riverscape connectivity.

\section{Quantifying Connectivity}

Connectivity is a vital element of natural landscapes, regulating the flow of genes, species, materials, and energy. However, human alteration of habitat often disrupts these flows, reducing connectivity and threatening biodiversity and ecosystem services worldwide [41-43]. River networks are especially susceptible to human-induced fragmentation effects due to their dendritic, linear structure [44, 45]. In fact, these connectivity relationships may be the most fundamental difference between riverscapes and terrestrial landscapes because the linear structure of rivers allows for disproportionately large effects of barriers. Studies show, for example, that hydropower dams can cause large - even continental scaledegradation of biodiversity and ecosystem services by reducing connectivity in freshwater networks [46-48]. Rarely could a single obstacle cause such extensive harm in terrestrial habitats, where alternative paths are often available to circumvent barriers. 
Stemming largely from these connectivity relationships, the application of graph analysis methods in riverscape research has yielded significant advances in ecological understanding and management of freshwater systems in the last decade $[13,49]$. With these methods, the effects of localized barriers can be quantified at the subcatchment or wholenetwork scale. For example, graph-based habitat availability indices were used to prioritize the removal of barriers in the catchment of the Tagus River, Portugal, to improve structural and functional connectivity $[50,51]$. Similarly, graphs were used to quantify fragmentation effects on river networks in the Great Plains region of the USA and to select regions where barrier mitigation or flow restoration would be most beneficial for maintaining or restoring fish biodiversity [52].

In addition to improving general ecological understanding and management strategies, forecasting the spread of invasive species based on riverscape connectivity is another valuable contribution of graph analyses. In a novel graph-based application, Chaput-Bardy et al. [53] modelled the spread of an invasive and a native reintroduced species in the catchment of the Loire River, France, and investigated how dispersal behavior influenced connectivity among habitat patches and colonization in the network (Fig. 2). Graph-based habitat availability analyses also proved useful for quantifying the structural connectivity and spatiotemporal variability of bar sediments in the braided-wandering Belá River, Slovakia [54]. As we discuss further in the next section, these graph-based approaches may represent a particularly important advance in quantifying the role of physical and biological connectivity not only in a spatially explicit manner, but also by facilitating the inclusion of temporal dynamics.

\section{Adding Temporal Dynamics to Riverscape Ecology}

Historical analysis of riverscapes is crucial to understanding how channel-floodplain habitats evolved over time, which provides key benchmarks for management. Although effects of hydromorphological turnover on the freshwater biodiversity have long been recognized (e.g., [18, 19, 55]), recent analyses have quantified the spatio-temporal development of riverscapes with unprecedented resolution (e.g., [56, 57]). In particular, these studies show the key effects of interactions with riparian and in-channel vegetation on hydromorphological dynamics $[58,59]$. This capacity of macrophyte vegetation to modify the physical environment has important implications for landform evolution and riparian biodiversity [58]. Further, in a series of excellent studies, Bishop-Taylor et al. [39, 60, 61] showed that remotely sensed time series data, both hydrologic and physical, can be combined with graph and circuit theory to evaluate changes in habitat availability for aquatic organisms over space and time across a complex riverscape. Their studies also show the advantages of combining dynamic, remotely sensed time series data with static landscape connectivity maps to characterize the structural and functional connectivity of the riverscape [61]. Such modelling approaches are needed to understand the consequences of large-scale drying and flooding on riverscape dynamics and connectivity patterns - a crucial step in predicting the effects of climate change on freshwater systems.

In addition to reconstructing the past, there is a pressing need to model and predict the future effects of climate change on riverscape ecology [62]. Studies predict, for example, significant shifts in the distribution of fishes with increasing water temperature and changes in precipitation. Generally, coldwater fishes are predicted to experience range reductions due to upstream shifts in habitat, whereas the ranges of warmwater fishes will likely expand [63, 64]. However, these climate-related effects will undoubtedly interact with the topology of river networks and other human perturbations (e.g., urbanization, reservoir construction), underscoring the importance of riverscape-scale predictive modelling $[65,66]$.

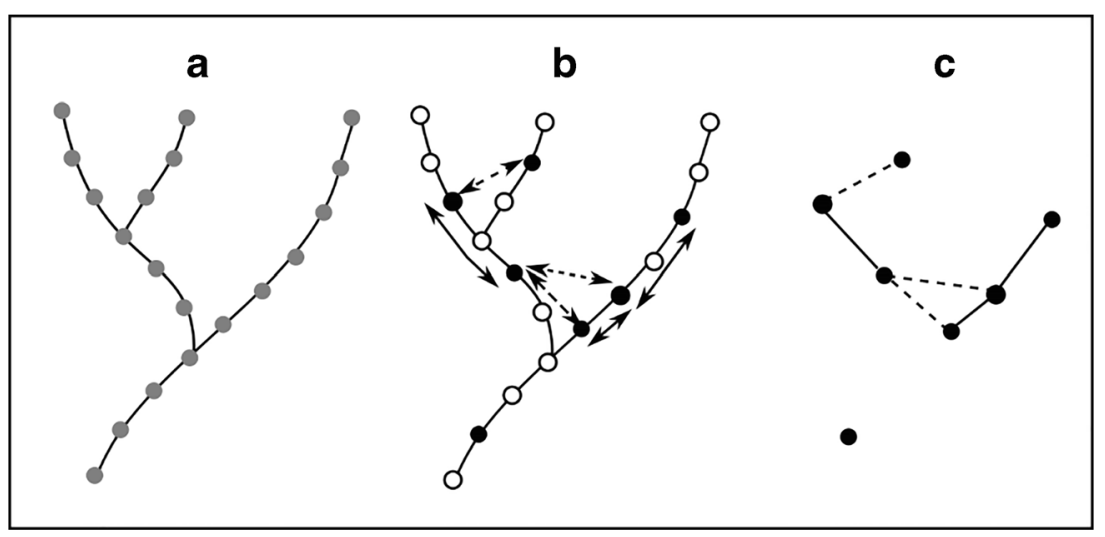

Fig. 2 Illustration of a graph-based approach for modelling landscapelevel processes in river networks, from Chaput-Bardy et al. (2017). In the first panel (a), the river network is modelled as a set of spatially discrete habitat patches (grey nodes). In the second panel (b), nodes are converted to represent ecological attributes of interest, such as species occupancy (black nodes: occupied, open nodes: unoccupied) and connectivity among occupied nodes is mapped based on the dispersal behavior of the focal species or fluxes of other biotic or abiotic materials (solid arrows: in-stream, dotted arrows: overland). In the third panel (c), the network is collapsed to a simplified graph capturing nodes of interest (e.g., occupied patches) and pathways of connectivity among those nodes 
Specifically, how species distributions and interactions (i.e., metacommunity dynamics) respond to climate change will almost certainly depend on the context of these processes within the larger river network.

\section{Q2: Pattern, Process, and Scale Relationships}

\section{Spatial Statistical Network Models}

One of the most important conceptual advances in understanding pattern, process, and scale relationships in riverscapes is the consideration of river networks as macrosystems. According to this concept, differences in spatial heterogeneity, connectivity, and asynchrony among elements of the network regulate ecological dynamics of the whole network, influencing system sensitivity, resistance, and resilience [67••]. Testing this concept requires spatially explicit, network-level statistical analyses developed recently by geostatistical modelers, and which offer valuable new insight on the scale dependence of hydrological and ecological patterns $[8 \bullet \bullet, 68]$.

These novel geostatistical modelling approaches account for specific properties of stream networks in analyzing the spatial structure of data (e.g., stream biochemistry, species density), including branching structure, directed flow, longitudinal connectivity, and abrupt changes at tributary confluences $[8 \cdot \bullet, 68]$. Models can account for two types of spatial relationships among data points based on hydrologic (i.e., non-Euclidean) distance: flow connected and flow unconnected. The flow-connected (or tail up) spatial autocorrelation structure may be useful for modelling downstream flows of material and energy, whereas the flow-unconnected (or tail down) model allows for spatial autocorrelation between both flowconnected and flow-unconnected sampling locations (e.g., points along a single tributary vs. points in adjacent, independent tributaries). The flow-unconnected spatial autocorrelation structure may be useful for modelling the abundance of organisms which can actively move both upstream and downstream (e.g., fish, amphibians, macroinvertebrates). For example, McGuire et al. [69] used 664 water samples collected every $100 \mathrm{~m}$ throughout 32 tributaries in a fifth-order river network to quantify spatial patterns of chemical constituents over a range of scales using empirical semivariograms that explicitly incorporated network topology. By examining the spatial dependence of the data, it was possible to separate the effects of fine- vs. broad-scale processes and in-stream vs. landscape processes on chemical variables. In another study, Filipe et al. [70] used these geostatistical analyses to better understand the distribution of invasive crayfish species in river networks.

In sum, these spatial statistical network models represent significant advances for quantifying and understanding the effects of network structure on patterns and processes in riverscapes. At present, however, this modelling framework operates with single response variables because the models are extensions of a basic linear model in which an autocovariance function is added to quantify the covariance between any two data points as a function of spatial distance. There is a great need for a multivariate analogue - similar models that accommodate multivariate response variables (e.g., community composition, multi-species abundance data, genotypes). Existing spatial statistical methods for multivariate response variables, such as partitioning variance between spatial and environmental fractions in redundancy analysis, have limited capacity to accommodate network properties, in addition to other weaknesses [71-73]. It would be especially useful if both univariate and multivariate response variables could be analyzed using the same modelling framework to ensure that differences in analytical methodology do not lead to differences in the interpretation of the results.

\section{Effect of Network Structure on Niche vs. Spatial Processes}

Despite the many recent conceptual and methodological advances in riverscape ecology, understanding how network structure mediates effects of environmental (i.e., niche based) vs. dispersal processes on biodiversity remains a central challenge. In an influential study, Brown and Swan [74] tested whether the influence of niche vs. dispersal processes changed depending on the position of habitat in the river network. Their results suggested that low-order, headwater streams are environmentally diverse and largely isolated from downstream elements of the network. As a consequence, local environmental conditions and species interactions should be the primary determinants of community structure in upstream areas, whereas the influence of dispersal should increase moving downstream (i.e., into higher-order streams), where habitats are in a more central position in the river network [74, 75]. Other theoretical studies predict strong effects of network structure on niche-based vs. dispersal processes, and on associated population or community dynamics [76-78], but empirical research has, thus far, found only weak support for the network position hypothesis (NPH; Schmera et al. [79]). In one of the most detailed, large-scale field studies using graph-based indices to examine the role of network position on community organization, HenriquesSilva et al. [80] found that (1) the NPH was not supported in catchments with high heterogeneity in connectivity among sites, and that (2) in more homogeneously connected catchments, the NPH was only supported when headwaters were more environmentally heterogeneous than downstream sites. Overall, these results suggest that environmental control, stochasticity, and the effects of 
human alteration override clear topological effects on communities in real riverscapes (see also [81]).

One of the most intriguing questions remaining in riverscape research is how ecological patterns and processes are affected by connectivity along the upstream-downstream gradient $[74,79,82]$, or by lateral hydrologic connectivity in large alluvial rivers [83, 84]. A growing number of studies suggest that local characteristics of the habitat (environmental heterogeneity, hydromorphology, etc.) are more important than spatial effects in determining population and community dynamics in riverscapes $[13,85]$. However, several studies also suggest that spatial dynamics can modify the effects of these local characteristics [86, 87], whether acting within stream channels, by overland pathways between channels, or between terrestrial and aquatic ecosystems [6, 81]. Recent conceptual papers thus emphasize the value of more mechanistic, spatially explicit approaches to understanding spatial population and community dynamics in riverscapes $[88 \cdot \bullet$, 89]. Specifically, these studies call for direct quantification of the movement of materials, energy, and organisms (e.g., dispersal, foraging, migration) along channels and across ecosystem boundaries. This "metaecosystem" view integrates the full spectrum of spatial connections among landscape elements, combining the core concepts of landscape and ecosystem ecology into a unified framework for spatial ecology research [88 • $]$. Measuring such a diversity of flows across a range of spatial and temporal scales is an extremely challenging task, but there is no doubt that these approaches offer unprecedented resolution of the structure and function of riverscapes [67]. Importantly, the use of direct data on the movement of materials, energy, and organisms guards against overreliance on indirect inference of spatial processes - a common problem in both landscape and riverscape research [90].

\section{Q3: Management Issues}

Understanding how environmental heterogeneity affects ecological patterns, processes, and scale relationships is necessary for scientifically sound management. Consequently, a key strength of landscape ecology has been its contributions to land use planning and land protection. In this regard, land sharing vs. land sparing debate is a pressing issue where scientific evaluation would be of great value. Land sparing refers to the protection of some land while the rest is used for agricultural production (or other ecosystem services), whereas land sharing requires the full protection of less land, but the use of more biodiversity-friendly strategies in agricultural landscapes $[91,92]$. We are only beginning to understand the trade-offs associated with these two strategies, but it is already clear that choices between land sharing vs. land sparing strategies not only affect terrestrial systems, but also the ecological status of riverscapes [93]. While it is also clear that conservation decisions for terrestrial systems cannot be separated from those related to the protection of river networks and riparian zones, integrated conservation planning for riverscapes has lagged, and conservation planning is typically conducted separately for terrestrial and freshwater systems [94, 95].

The catchments of streams and rivers encompass both terrestrial and aquatic landscapes, and functional catchments maintain the natural flows of elements, material, energy, and organisms between the two realms [96, 97]. Therefore, it is logical that catchments should be the basic units of conservation management, rather than basing management on terrestrial landscape elements or jurisdictional boundaries [98]. Fortunately, recent management frameworks recognize the need for spatially informed and strategic approaches that protect biodiversity and ecosystem services at the catchment scale [99-101•, 102]. For example, Erös et al. [101•] propose a unified model for riverscape conservation that systematically guides management actions to protect both terrestrial and aquatic biodiversity and ecosystem services. This framework suggests applying biodiversity and ecosystem service indicators to prioritize land use within and among catchments, and an optimization-based approach for identifying the most suitable catchments for protection that incorporates connectivity restoration. This approach is thus based on a combination of land sparing and land sharing strategies to achieve sustainable water resources.

Spatial prioritization and optimization approaches can help to guide conservation by placing riverscape elements (e.g., stream reaches, segments, subcatchments) into three key categories: (1) of priority for conservation and/or rehabilitation to a closely natural state (e.g., based on biodiversity, regeneration potential, nutrient retention, ecotourism potential), (2) primarily for human use (e.g., reservoirs for water storage and/or electricity, canals for irrigation), and (3) for both conservation functions and human use according to societal needs and intentions (Fig. 3). The hierarchical, patch-based model of riverine macrosystem ecology provides a useful template to delineate riverscape elements (or functional process zones) in these different management categories (Fig. 3). Spatially explicit optimization, in turn, can identify the longest or largest sequence of riverscape elements within each category, allowing for the prioritization of areas for conservation, rehabilitation, or intensive human use

With climate change, freshwater management will continue to be a critical issue for humankind, and this "battle for water" will likely accelerate the deterioration of riverscapes. Sustainable management of riverscapes will thus necessitate not only intensive negotiations among stakeholder groups, but also creative uses of socio-economic and socio-ecological data to find compromise in the land sparing vs. land sharing debate 


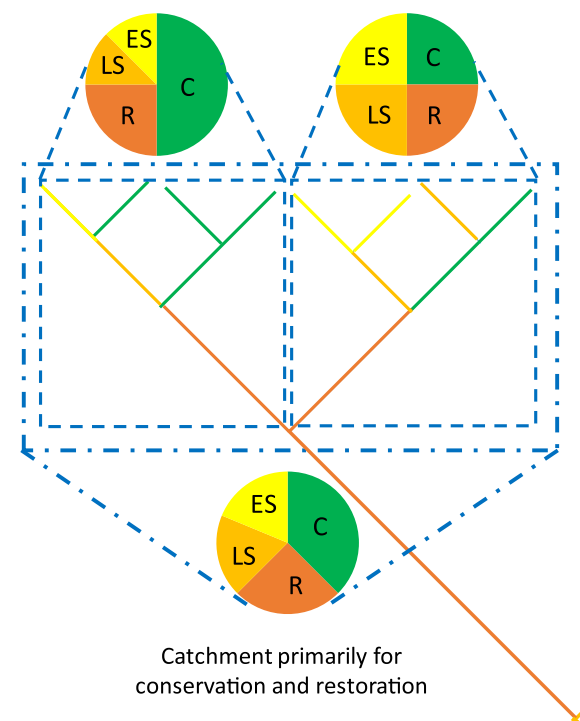

conservation and restoration

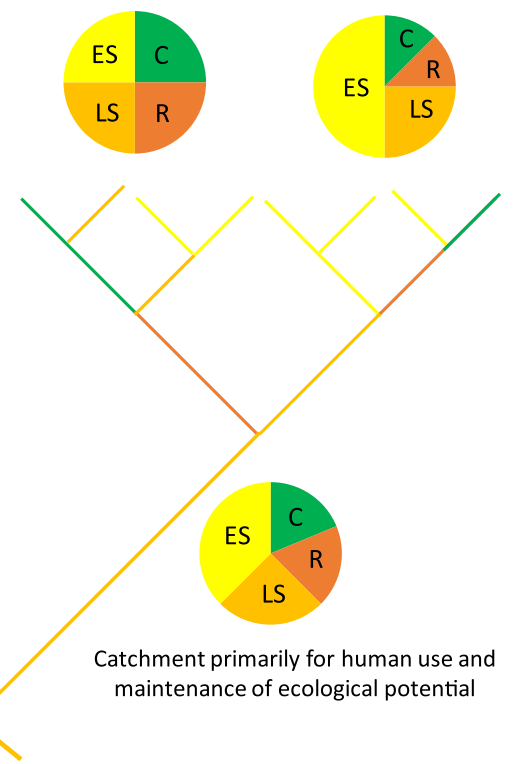

conceptual illustration, both catchments (lower pie charts) encompass diverse functions, as shown by the composition of constitutive subcatchments (upper pie charts). However, the left catchment is more suitable for conservation and related ecosystem services, while the right catchment is more suitable for human use and related services. The branching hierarchy represents subcatchments of different size, with colors corresponding to channel segments with specific management targets $(\mathrm{C}, \mathrm{R}, \mathrm{ES}, \mathrm{LS})$

expand in numbers and power. Recent studies also show the versatility of spatial graph and network models for understanding and interpreting scale-dependent patterns and processes in riverscapes. Specifically, spatially explicit network approaches are able to quantify and predict biogeochemical, hydromorphological, and ecological patterns and processes more precisely than models based on longitudinal or lateral riverine gradients alone. Finally, we see great value in coupling spatially explicit riverscape models with optimization approaches to guide land protection, water management, and to resolve the land sharing vs. land sparing debate.

Despite these great strides in modelling and applications, there remain many unanswered questions related to ecological structure and function in riverscapes. One striking example comes from recent satellite imagery and modelling analyses suggesting that the length and surface area of river networks is much higher than previously thought [105]. Among many important implications, these findings suggest that riverscapes play a greater role in controlling land-atmosphere carbon fluxes than is currently represented in global budgets, and call for explicit integration of riverscape and climate models. More broadly, this study makes clear the need for more innovative technological, analytical, and modelling tools to understand and protect ecological processes occurring within riverscapes, as well as those involving interactions with terrestrial and atmospheric systems. of gradient-based models to riverscape ecology will likely 
Authors' Contribution TE conceived the main ideas of the study and led writing of the manuscript with the contribution of WL. Both TE and WL contributed to editing manuscript drafts and gave final approval for publication.

Funding Information Open access funding provided by MTA Centre for Ecological Research (MTA ÖK). The work of TE was supported by the GINOP 2.3.3-15-2016-00019 and the Ecology for Society (MTA KEP) project.

\section{Compliance with Ethical Standards}

Conflict of Interest The authors have no conflict of interest.

Human and Animal Rights and Informed Consent This article does not contain any studies with human or animal subjects performed by any of the authors.

Open Access This article is distributed under the terms of the Creative Commons Attribution 4.0 International License (http:// creativecommons.org/licenses/by/4.0/), which permits unrestricted use, distribution, and reproduction in any medium, provided you give appropriate credit to the original author(s) and the source, provide a link to the Creative Commons license, and indicate if changes were made.

\section{References}

Papers of particular interest, published recently, have been highlighted as:

- Of importance

- Of major importance

1. Turner MG, Gardner RH. Introduction to landscape ecology and scale. In: Landscape Ecology in Theory and Practice. Springer, New York, NY, USA; 2015. p. 1-32.

2. Wu JG. Key concepts and research topics in landscape ecology revisited: 30 years after the Allerton Park workshop. Landsc Ecol. 2013;28:1-11.

3. Wiens JA. Riverine landscapes: taking landscape ecology into the water. Freshw Biol. 2002;47:501-15.

4. Allan JD. Landscapes and riverscapes: the influence of land use on stream ecosystems. Annu Rev Ecol Evol Syst. 2004;35:257-84.

5. Wu J. Seascape ecology and landscape ecology: distinct, related, and synergistic. In: Simon J. Pittman (editor), Seascape Ecology, Wiley-Blackwell. 2018; p. 487-491.

6. Erös T, Campbell-Grant EH. Unifying research on the fragmentation of terrestrial and aquatic habitats: patches, connectivity and the matrix in riverscapes. Freshw Biol. 2015;60:1487-501.

7. Fausch KD, Torgersen CE, Baxter CV, Li HW. Landscapes to riverscapes: bridging the gap between research and conservation of stream fishes. Bioscience. 2002;52:483-98.

8.• Peterson EE, Ver Hoef JM, Isaak DJ, Falke JA, Fortin MJ, Jordan $\mathrm{CE}$, et al. Modelling dendritic ecological networks in space: an integrated network perspective. Ecol Lett. 2013;16:707-19 This study provides an overview of spatial statistical network models for dendritic stream networks.

9. Vannote RL, Minshall GW, Cummins KW, Sedell JR, Cushing CE. The river continuum concept. Can J Fish Aquat Sci. 1980;37:130-7.
10. Benda L, Poff NL, Miller D, Dunne T, Reeves G, Pess G, et al. The network dynamics hypothesis: how channel networks structure riverine habitats. Bioscience. 2004;54:413-27.

11. Campbell Grant EH, Lowe WH, Fagan WF. Living in the branches: population dynamics and ecological processes in dendritic networks. Ecol Lett. 2007;10:165-75.

12. Altermatt F. Diversity in riverine metacommunities: a network perspective. Aquat Ecol. 2013;47:365-77.

13. Erős T. Scaling fish metacommunities in stream networks. Synthesis and future research avenues. Community Ecol. 2017;18:72-86.

14. Tonkin JD, Altermatt F, Finn DS, Heino J, Olden JD, Pauls SU, et al. The role of dispersal in river network metacommunities: patterns, processes, and pathways. Freshw Biol. 2018;63:141-63 An important synthesis of current knowledge on the role of dispersal in stream metacommunities.

15. Lausch A, Blaschke T, Haase D, Herzog F, Syrbe R-U, Tischendorf $\mathrm{L}$, et al. Understanding and quantifying landscape structure - a review on relevant process characteristics, data models and landscape metrics. Ecol Model. 2015;295:31-41.

16. Turner MG. Landscape ecology: the effect of pattern on process. Annu Rev Ecol Syst. 1989;20:171-97.

17. McGarigal K, Tagil S, Cushman SA. Surface metric: an alternative to patch metrics for the quantification of landscape structure. Landsc Ecol. 2009;24:433-50.

18. Poole GC. Fluvial landscape ecology: addressing uniqueness within the river discontinuum. Freshw Biol. 2002;47:641-60.

19. Thorp JH, Thoms MC, Delong MD. The riverine ecosystem synthesis: biocomplexity in river networks across space and time. River Res Appl. 2006;22:123-47.

20. Thorp JH. Metamorphosis in river ecology: from reaches to macrosystems. Freshw Biol. 2014;59:200-10.

21. Thorp JH, Flotemersch JE, Delong MD, Casper AF, Thoms MC, Ballantyne F, et al. Linking ecosystem services, rehabilitation, and river hydrogeomorphology. Bioscience. 2010;60:67-74.

22. Hitchman SM, Mather ME, Smith JM, Fencl JS. Identifying keystone habitats with a mosaic approach can improve biodiversity conservation in disturbed ecosystems. Glob Chang Biol. 2018;24: 308-21.

23. Thoms M, Scown M, Flotemersch J. Characterization of river networks: A GIS approach and its applications. J Am Water Resour As. 2018;1-15.

24. Bechter T, Baumann K, Birk S, Bolik F, Graf W, Pletterbauer F. LaRiMo - a simple and efficient GIS-based approach for largescale morphological assessment of large European rivers. Sci Total Environ. 2018;628:1191-9.

25. Rusnák M, Sládek J, Kidová A, Lehotský M. Template for highresolution river landscape mapping using UAV technology. Measurement. 2018;115:139-51.

26. Scown MW, Thoms MC, DeJager NR. Measuring floodplain spatial patterns using continuous surface metrics at multiple scales. Geomorphology. 2015;245:87-101.

27. Cook KL. An evaluation of the effectiveness of low-cost UAVsand structure from motion for geomorphic change detection. Geomorphology. 2017;278:195-208.

28. Bizzi S, Demarchi L, Grabowski RC, Weissteiner CJ, Van de Bund $W$. The use of remote sensing to characterise hydromorphological properties of European rivers. Aquat Sci. 2016;78:57-70.

29. Belletti B, Rinaldi M, Bussettini M, Comiti F, Gurnell AM, Mao $\mathrm{L}$, et al. Characterising physical habitats and fluvial hydromorphology: a new system for the survey and classification of river geomorphic units. Geomorphology. 2017;283:143-57.

30. Erős T, Olden JD, Schick RS, Schmera D, Fortin M. Characterizing connectivity relationships in freshwaters using patch-based graphs. Landsc Ecol. 2012;27:303-17. 
31. Frazier AE, Kedron P. Landscape metrics: past progress and future directions. Curr Landscape Ecol Rep. 2017;2:63-72.

32. Baranya S, Fleit G, Józsa J, Szalóky Z, Tóth B, Erös T. Habitat mapping of riverine fish by means of hydromorphological tools. Ecohydrology. 2018;11:e2009.

33. Cavanaugh KC, Siegel DA, Raimondi PT, Alberto F. Patch definition in metapopulation analysis: a graph theory approach to solve the mega-patch problem. Ecology. 2014;95:316-28.

34. Dilts TE, Weisberg PJ, Leitner P, Matocq MD, Inman RD, Nussear $\mathrm{KE}$, et al. Multiscale connectivity and graph theory highlight critical areas for conservation under climate change. Ecol Appl. 2016;26:1223-37.

35. Fall A, Fortin M-J, Manseau M, O’Brien D. Spatial graphs: principles and applications for habitat connectivity. Ecosystems. 2007;10:448-61.

36. Dale MRT, Fortin M-J. From graphs to spatial graphs. Annu Rev Ecol Evol Syst. 2010;41:21-38.

37. Galpern P, Manseau M, Fall A. Patch-based graphs of landscape connectivity: a guide to construction, analysis and application for conservation. Biol Conserv. 2011;144:44-55.

38. Fullerton AH, Anzalone S, Moran P, Van Doornik DM, Copeland T, Zabel RW. Setting spatial conservation priorities despite incomplete data for characterizing metapopulations. Ecol Appl. 2016;26: 2560-80.

39. Bishop-Taylor R, Tulbure MG, Broich M. Surface-water dynamics and land use influence landscape connectivity across a major dryland region. Ecol Appl. 2017;27:1124-37.

40. Neufeld K, Watkinson DA, Tierney K, Poesch MS. Incorporating asymmetric movement costs into measures of habitat connectivity to assess impacts of hydrologic alteration to stream fishes. Divers Distrib. 2018;24:593-604.

41. Fahrig L. Effects of habitat fragmentation on biodiversity. Annu Rev Ecol Evol S. 2003;34:487-515.

42. Nilsson C, Reidy CA, Dynesius M, Revenga C. Fragmentation and flow regulation of the world's large river systems. Science. 2005;308:405-8.

43. Fisher J, Lindenmayer DB. Landscape modification and habitat fragmentation: a synthesis. Glob Ecol Biogeogr. 2007;16:265-80.

44. Fagan WF. Connectivity, fragmentation, and extinction risk in dendritic metapopulations. Ecology. 2002;83:3243-9.

45. Crook DA, Lowe WH, Allendorf FW, Erös T, Finn DS, Gillanders BM, Hadwen WL, Harrod C, Hermoso V, Jennings S, Kilada RW, Nagelkerken I, Hansen MM, Page TJ, Riginos C, Fry B, Hughes JM. Human effects on ecological connectivity in aquatic ecosystems. Integrating scientific approaches to support management and mitigation. Sci Total Environ. 2015;534:52-64.

46. Wu J, Huang J, Han X, Xie Z, Gao X. Three-gorges-dam - experiment in habitat fragmentation? Science. 2003;300:1239-40.

47. Poff NLR, Olden JD, Merritt DM, Pepin DM. Homogenization of regional river dynamics by dams and global biodiversity implications. PNAS. 2007;104:5732-7.

48. Ziv G, Baran E, Nam S, Rodríguez-Iturbe I, Levin SA. Trading-off fish biodiversity, food security, and hydropower in the Mekong River Basin. P Natl A Sci. 2012;109:5609-14.

49. Erős T, Schmera D, Schick RS. Network thinking in riverscape conservation - a graph-based approach. Biol Conserv. 2011;144: 184-92.

50. Segurado P, Branco T, Ferreira MT. Prioritizing restoration of the structural connectivity of rivers: a graph-based approach. Landsc Ecol. 2013;28:1231-8.

51. Branco P, Segurado P, Santos JM, Ferreira MT. Prioritizing barrier removal to improve functional connectivity of rivers. J Appl Ecol. 2014;51:1197-206.

52. Perkin JS, Gido KB, Cooper AR, Turner TF, Osborne MJ, Johnson ER, et al. Fragmentation and dewatering transform
Great Plains stream fish communities. Ecol Monogr. 2015;85: 73-92.

53. Chaput-Bardy A, Alcala N, Secondi J, Vuilleumier S. Network analysis for species management in river networks: application to the Loire River. Biol Conserv. 2017;210:26-36.

54. Lehotský M, Rusnák M, Kidová A, Dudžák J. Multitemporal assessment of coarse sediment connectivity along a braidedwandering river. Land Degrad Dev. 2018;29:1249-61.

55. Townsend CR. The patch dynamics concept of stream community ecology. J N Am Benthol Soc. 1989;8:36-50.

56. Hohensinner S, Jungwirth M, Muhar S, Schmutz S. Spatiotemporal habitat dynamics in a changing Danube River landscape 1812-2006. River Res Appl. 2011;27:939-55.

57. Díaz-Redondo M, Marchamalo M, Egger G, Magdaleno F. Toward floodplain rejuvenation in the middle Ebro River (Spain): from history to action. Geomorphology. 2018;317:11727.

58. Francis RA, Corenblit D, Edwards PJ. Perspectives on biogeomorphology, ecosystem engineering and self-organization in island-braided fluvial ecosystems. Aquat Sci. 2009;71:290 304.

59. Gurnell AM, Rinaldi M, Belletti B, Bizzi S, Blamauer B, Braca G, et al. A multi-scale hierarchical framework for developing understanding of river behaviour to support river management. Aquat Sci. 2016;78:1-16.

60. Bishop-Taylor R, Tulbure MG, Broich M. Evaluating static and dynamic landscape connectivity modelling using a 25 -year remote sensing time series. Landsc Ecol. 2018b;33:625-40.

61. Bishop-Taylor R, Tulbure MG, Broich M. Evaluating static and dynamic landscape connectivity modelling using a 25-year remote sensing time series. Landscape Ecol. 2018b;33:625-640.

62. Knouft JH, Ficklin DL. The potential impacts of climate change on biodiversity in flowing freshwaters systems. Annu Rev Ecol Evol S. 2017;48:111-33.

63. Buisson L, Thuiller W, Lek S, Lim P, Grenouillet G. Climate change hastens the turnover of stream fish assemblages. Glob Chang Biol. 2008;14:2232-48.

64. Comte L, Grenouillet G. Do stream fish track climate change? Assessing distribution shifts in recent decades. Ecography. 2013;36:1236-46.

65. Markovic D, Freyhof J, Wolter C. Where are all the fish: potential of biogeographical maps to project current and future distribution patterns of freshwater species. PLoS One. 2012;7:e40530.

66. Radinger J, Hölker F, Horký P, Slavík O, Dendoncker N, Wolter C. Synergistic and antagonistic interactions of future land use and climate change on river fish assemblages. Glob Chang Biol. 2016;22:1505-22.

67.• McCluney KE, Poff NL, Palmer MA, Thorp JH, Poole GC, Williams BS, et al. Riverine macrosystems ecology: sensitivity, resistance, and resilience of whole river basins with human alterations. Front Ecol Environ. 2014;12:48-58 This study shows a useful template to view riverscapes from a macrosystem perspective.

68. Isaak DJ, Peterson EE, Ver Hoef JM, Wenger SJ, Falke JA, Torgersen CE, et al. Applications of spatial statistical network models to stream data. WIREs Water. 2014;1:277-94.

69. McGuire KJ, Torgersen CE, Likens GE, Buso DC, Lowe WH, Bailey SW. Network analysis reveals multiscale controls on streamwater chemistry. P Natl Acad Sci USA. 2014;111:7030 7035.

70. Filipe AF, Quaglietta L, Ferreira M, Magalhães MF, Beja P. Geostatistical distribution modelling of two invasive crayfish across dendritic stream networks. Biol Invasions. 2017;19:2899 912.

71. Gilbert B, Bennett JR. Partitioning variation in ecological communities: do the numbers add up? J Appl Ecol. 2010;47:1071-82. 
72. Smith TW, Lundholm JT. Variation partitioning as a tool to distinguish between niche and neutral processes. Ecography. 2010;33: 648-55.

73. Sály P, Erös T. Effect of field sampling design on variation partitioning in a dendritic stream network. Ecol Complex. 2017;28:187-99.

74. Brown BL, Swan CM. Dendritic network structure constrains metacommunity properties in riverine ecosystems. J Anim Ecol. 2010;79:571-80.

75. Göthe E, Angeler DG, Sandin L. Metacommunity structure in a small boreal stream network. J Anim Ecol. 2013;82:449-58.

76. Labonne J, Ravigné V, Parisi B, Gaucherel C. Linking dendritic network structures to population demogenetics: the downside of connectivity. Oikos. 2008;117:1479-90.

77. Auerbach DA, Poff NL. Spatiotemporal controls of simulated metacommunity dynamics in dendritic networks. J N Am Benthol Soc. 2011;30:235-51.

78. Terui A, Ishiyama N, Urabe H, Ono S, Finlay JC, Nakamura F. (2018). Metapopulation stability in branching river networks. P Natl Acad Sci USA 2018;115:E5963-E5969.

79. Schmera D, Árva D, Boda P, Bódis E, Bolgovics Á, Borics G, et al. Does isolation influence the relative role of environmental and dispersal-related processes in stream networks? An empirical test of the network position hypothesis using multiple taxa. Freshw Biol. 2018;63:74-85.

80. Henriques-Silva R, Logez M, Reynaud N, Tedesco PA, Brosse S, Januchowski-Hartley SR, et al. A comprehensive examination of the network position hypothesis across multiple river metacommunities. Ecography. 2018;42:284-94.

81. Tonkin JD, Heino J, Sundermann A, Haase P, Jähnig SC. Context dependency in biodiversity patterns of central German stream metacommunities. Freshw Biol. 2016;61:607-20.

82. Lowe WH. Landscape-scale spatial population dynamics in human-impacted stream systems. Environ Manag. 2002;30:22533.

83. Ward J, Tockner K, Uehlinger U, Malard F. Understanding natural patterns and processes in river corridors as the basis for effective river restoration. Regul Rivers: Res Mgmt. 2001;17:311-23.

84. Hauer FR, Locke H, Dreitz VJ, Hebblewhite M, Lowe WH, Muhlfeld CC, et al. Gravel-bed river floodplains are the ecological nexus of glaciated mountain landscapes. Sci Adv. 2016;2: e1600026.

85. Heino J, Melo AS, Siqueira T, Soininen J, Valanko S, Bini LM. Metacommunity organisation, spatial extent and dispersal in aquatic systems: patterns, processes and prospects. Freshw Biol. 2015;60:845-69.

86. Lowe WH. Linking dispersal to local population dynamics: a case study using a headwater salamander system. Ecology. 2003;84: 2145-54.

87. Czeglédi I, Sály P, Takács P, Dolezsai A, Nagy SA, Erős T. The scales of variability of stream fish assemblages at tributary confluences. Aquat Sci. 2015;78:641-54.

88. • Gounand I, Harvey E, Little CJ, Altermatt F. Meta-ecosystems 2.0: rooting the theory into the field. Trends Ecol Evol. 2018;33:36-46 An important contribution which emphasizes the better integration of landscape ecology and meta-ecosystem ecology into a single framework of spatial ecology.

89. Loreau M, Mouquet N, Gonzalez A. Biodiversity as spatial insurance in heterogeneous landscapes. Proc Natl Acad Sci. 2003;100: 12765-70.
90. Lowe WH, McPeek MA. Is dispersal neutral? Trends Ecol Evol. 2014;29:444-50.

91. Green RE, Cornell SJ, Scharlemann JPW, Balmford A. Farming and the fate of wild nature. Science. 2005;307:550-5.

92. Fisher J, Abson DJ, Butsic V, Chappell MJ, Ekroos J, Hanspach J, et al. Land sparing versus land sharing: moving forward. Conserv Lett. 2014;7:149-57.

93. Koning AA, Moore J, Suttidate N, Hannigan R, McIntyre PB. Aquatic ecosystem impacts of land sharing versus sparing: nutrient loading to Southeast Asian rivers. Ecosystems. 2017;20:393405.

94. Abell R, Allan JD, Lehner B. Unlocking the potencial of protected areas for freshwaters. Biol Conserv. 2007;134:48-63.

95. Nel JL, Reyers B, Roux DJ, Cowling RM. Expanding protected areas beyond their terrestrial comfort zone: identifying spatial options for river conservation. Biol Conserv. 2009;142:1605-16.

96. Liken GE, Bormann FH. Linkages between terrestrial and aquatic ecosystems. Bioscience. 1974;24:447-56.

97. Lowe WH, Likens GE. Moving headwater streams to the head of the class. Bioscience. 2005;55:196-7.

98. Doody DG, Withers PJA, Dils RM, McDowell RW, Smith V, McElarney YR, et al. Optimizing land use for the delivery of catchment ecosystem services. Front Ecol Environ. 2016;14: 325-32.

99. Terrado M, Momblanch A, Bardina M, Boithias L, Munné A, Sabater S, et al. Integrating ecosystem services in river basin management plans. J Appl Ecol. 2016;53:865-75.

100. Zheng H, Li Y, Robinson BE, Liu G, Ma D, Wang F, et al. Using ecosystem service trade-offs to inform water conservation policies and management practices. Front Ecol Environ. 2016;14:527-32.

101. Erős T, O’Hanley JR, Czeglédi I. A unified model for optimizing riverscape conservation. J Appl Ecol. 2018;55:1871-83 This study presents a modelling framework to directly integrate and optimize river conservation, ecosystem services delivery, and connectivity restoration planning.

102. Hermoso V, Cattarino L, Linke S, Kennard MJ. Catchment zoning to enhance co-benefits and minimize trade-offs between ecosystem services and freshwater biodiversity conservation. Aquatic Conserv: Mar Freshw Ecosyst. 2018;28:1004-14.

103. Palomo I, Montes C, Martín-López B, González JA, GarcíaLlorente M, Alcorlo P, et al. Incorporating the socio-ecological approach in protected areas in the Anthropocene. Bioscience. 2014;64:181-91.

104. • Poff NL, Brown CM, Grantham TE, Matthews JH, Palmer MA, Spence CM, et al. Sustainable water management under future uncertainty with eco-engineering decision scaling. Nat Clim Chang. 2016;6:25 A decision framework that explicitly and quantitatively explores trade-offs in engineering and ecological performance metrics across a range of management actions under unknown future hydrological and climate states.

105. Allen GH, Pavelsky TM. Global extent of rivers and streams. Science. 2018;361:585-8.

Publisher's Note Springer Nature remains neutral with regard to jurisdictional claims in published maps and institutional affiliations. 